\title{
Suitability evaluation of land development based on the green infrastructure assessment
}

\author{
The case of Harbin
}

Rong GUO, School of Architecture, Harbin Institute of Technology; Key Laboratory of Cold Region Urban and Rural Human Settlement Environment Science and Technology, Ministry of Industry and Information Technology; 66 West Dazhi Street, Nangang District, Harbin 150006, China

Yujing BAI, School of Architecture, Harbin Institute of Technology; Key Laboratory of Cold Region Urban and Rural Human Settlement Environment Science and Technology, Ministry of Industry and Information Technology, China

Ye GAO, School of Architecture, Harbin Institute of Technology; Key Laboratory of Cold Region Urban and Rural Human Settlement Environment Science and Technology, Ministry of Industry and Information Technology, China

\begin{abstract}
It is an important basis for optimizing land spatial patterns and guiding land spatial planning to clarify the ecological conditions of land space, arrange reasonably agricultural production and urban-rural construction space. The network formed by green infrastructures has important ecological significance in maintaining the migration of biological species and ensuring the continuity of the ecological process. Based on the concept of ecological priority and green development, this paper constructs a framework of the land space development suitability evaluation based on green infrastructure evaluation. From the perspective of ecosystem service value and ecological sensitivity, the evaluation factors are selected to make a comprehensive evaluation of green infrastructure. The evaluation results are the basis for the evaluation of the importance of ecological protection, the suitability of agricultural production, and the suitability of construction. At last, taking Harbin as an example, the evaluation framework is applied to preliminarily determine the red line of ecological protection and the scope of ecological space, agricultural space, and urban-rural construction space in 2015. It is expected to provide a reference basis for the compilation of land and space planning in Harbin.
\end{abstract}

\section{Keywords}

green infrastructure, land space development suitability evaluation, ecosystem service value, ecological sensitivity, Harbin

\section{Introduction}

The suitability of land development means refers to the suitability of land space for different development and utilization modes, such as ecological maintenance, agricultural production, and urban construction (Fan, 2019). The land suitability evaluation has become a basic part of land planning analysis (Hopkins, 1977). The suitability evaluation aims to identify various land functional spaces, and further to delimit ecological protection red lines, permanent basic farmland red lines, and urban development boundaries. It is an important topic to optimize land space patterns and make land space planning. However, existing studies on land suitability evaluation focus on agricultural land (Nisar Ahamed, Gopal Rao and Murthy, 2000; Kalogirou, 2002; Prakash TN, 2003; Sicat, Carranza and Nidumolu, 2005). In this 
paper, the suitability evaluation of land development points at ecological, production, and living functions of land use, including the importance evaluation of ecological protection, the suitability evaluation of agricultural production, and the suitability evaluation of urban-rural construction. Among these three evaluation work, the importance evaluation of ecological protection is of priority, to ensure the security of regional key ecological resources. Thus, to promote the green sustainable development of the region.

The GIS-based fuzzy multicriteria decision-making approach often is used to evaluate land suitability (Joerin, Thérialult and Musy, 2001; Prakash TN, 2003). This paper also uses GIS, coupling with green infrastructure assessment to evaluate land suitability. The green infrastructure (GI) contains all kinds of natural and semi-natural blue-green areas, such as green spaces, nature reserves, farmland, wetlands, forests, rivers, and other resources with ecological value (The North West Green Infrastructure Think Tank, 2008; Naumann et al., 2011; Ely and Pitman, 2014; Wu et al., 2018). These green infrastructures can maintain and improve ecosystem services, and thus provide multi-benefits for the human, animal, and plant survival (European Commission, 2012; Conbere et al., 2014; Xing, Jones and Donnison, 2017). The suitability evaluation of land development based on green infrastructure assessment not only consider the ecosystem services provided by a single patch but also can advance the continuity and integrity of the horizontal ecological process. Therefore, this paper proposes the idea of evaluating the importance of ecological protection, the suitability of agricultural production, and the suitability of urbanrural construction for land space based on the results of green infrastructure assessment.

\section{Methods}

Given the advantage of combining green infrastructure assessment with the suitability study of land development, this paper puts forward the framework for the suitability evaluation of land development based on green infrastructure assessment (Figure 1).

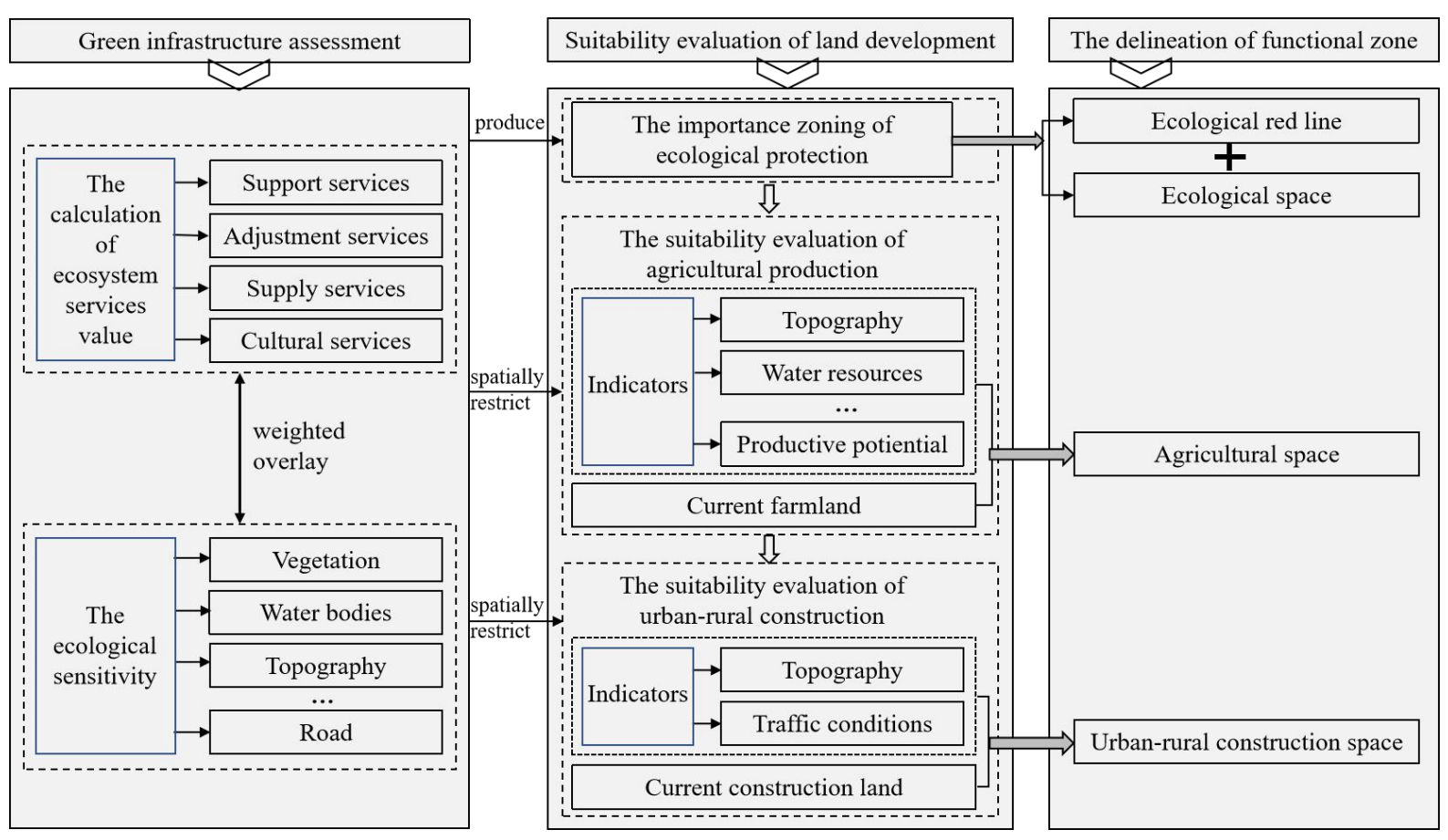

Figure 1. The study framework for suitability evaluation of land development based on green infrastructure assessment. Source: the authors. 


\subsection{Green infrastructure assessment}

This paper establishes a green infrastructure assessment system from the perspectives of ecosystem services value and ecological sensitivity (Table 1). Ecosystem services provided by the green infrastructure can be classified into support, adjustment, supply, and cultural services (Alcamo et al., 2003; Liu et al., 2013). The value of each service can be calculated according to the equivalents of ecosystem service value in China (Xie et al., 2015). Thus, to obtain the total ecosystem services value of green infrastructure. As to the ecological sensitivity of green infrastructure, the selection of indicators can consider from vegetation, water bodies, topography, and so on, coupling with the characteristics of the study area. To avoid the reduction of sensitivity in some constraint factors after weighted overlaying, this paper uses the maximum method to create the results of ecological sensitivity. At last, 10 experts in the fields of landscape, ecology, and urban-rural planning are invited to score for the relative importance between ecosystem services value and ecological sensitivity in the work of assessing green infrastructure. The average score of these experts is used to combine the results of ecosystem services value calculation and ecological sensitivity evaluation.

Table 1. The indicator system of green infrastructure assessment. Source: the authors.

\begin{tabular}{llll}
\hline Target layer & System layer & Factor layer & Indicators \\
\hline Green & Ecosystem & Support services & Biodiversity, soil \\
infrastructure & services value & Adjustment services & Climate, air, water \\
& & Supply services & Food, water resources \\
& & Cultural service & Esthetics \\
\cline { 2 - 3 } & Ecological & Vegetation & Reserves, parks, forests, farmland \\
& sensitivity & Water bodies & Rivers, reservoirs, lakes \\
& & Topography & Slope, topographic relief \\
& Road & road \\
\hline
\end{tabular}

\subsection{The suitability evaluation of land development}

The suitability evaluation of land development consists of the importance evaluation of ecological protection, the suitability evaluation of agricultural production, and the suitability evaluation of urbanrural construction. The importance zoning of ecological protection can be obtained through the results of green infrastructure assessment. Areas with higher ecological importance in green infrastructure assessment will be classified as prohibited zones for agricultural and construction land development. That is the range of the red line of ecological protection. The suitability evaluation of agricultural production and the suitability evaluation of urban-rural construction only be carried out for areas beyond the red line of ecological protection. In the procedure of the suitability evaluation of agricultural production only use the productive potential of the land as an indicator. Because productive potential data used in this paper contain factors like topography, climate, and water resources, etc. Besides, due to the limitation of data acquisition, the suitability evaluation of urban-rural construction in this paper merely considers topography and traffic conditions. Following these evaluated results, combined with the current land use situation, the paper can preliminarily determine the scope of ecological spaces, agricultural spaces, and urban-rural construction spaces. 


\section{Study area and data source}

Harbin locates in northeast China, which is the captain of Heilongjiang Province (Figure 2). The administrative area is $53,100 \mathrm{~km}^{2}$, including Harbin city, Wuchang city, Shangzhi city, Bayan county, Bin county, Mulan county, Tonghe county, Yilan county, Fangzheng county, Yanshou county. There are abundant agricultural resources, forest resources, animal resources, and so on in Harbin. The terrain is flat near Harbin city. Due to unreasonable urban development in the earlier period, Harbin is also facing the contradiction between ecological protection and urban-rural development. Therefore, this paper applies the proposed framework to evaluate the suitability of land development in Harbin. Based on the evaluated results, ecological spaces, agricultural spaces, and urban-rural construction spaces of Harbin can be delineated. Furthermore, the scope of the red line of ecological protection can also be preliminarily determined. It is significant for promoting green and sustainable development of Harbin land spatial patterns.

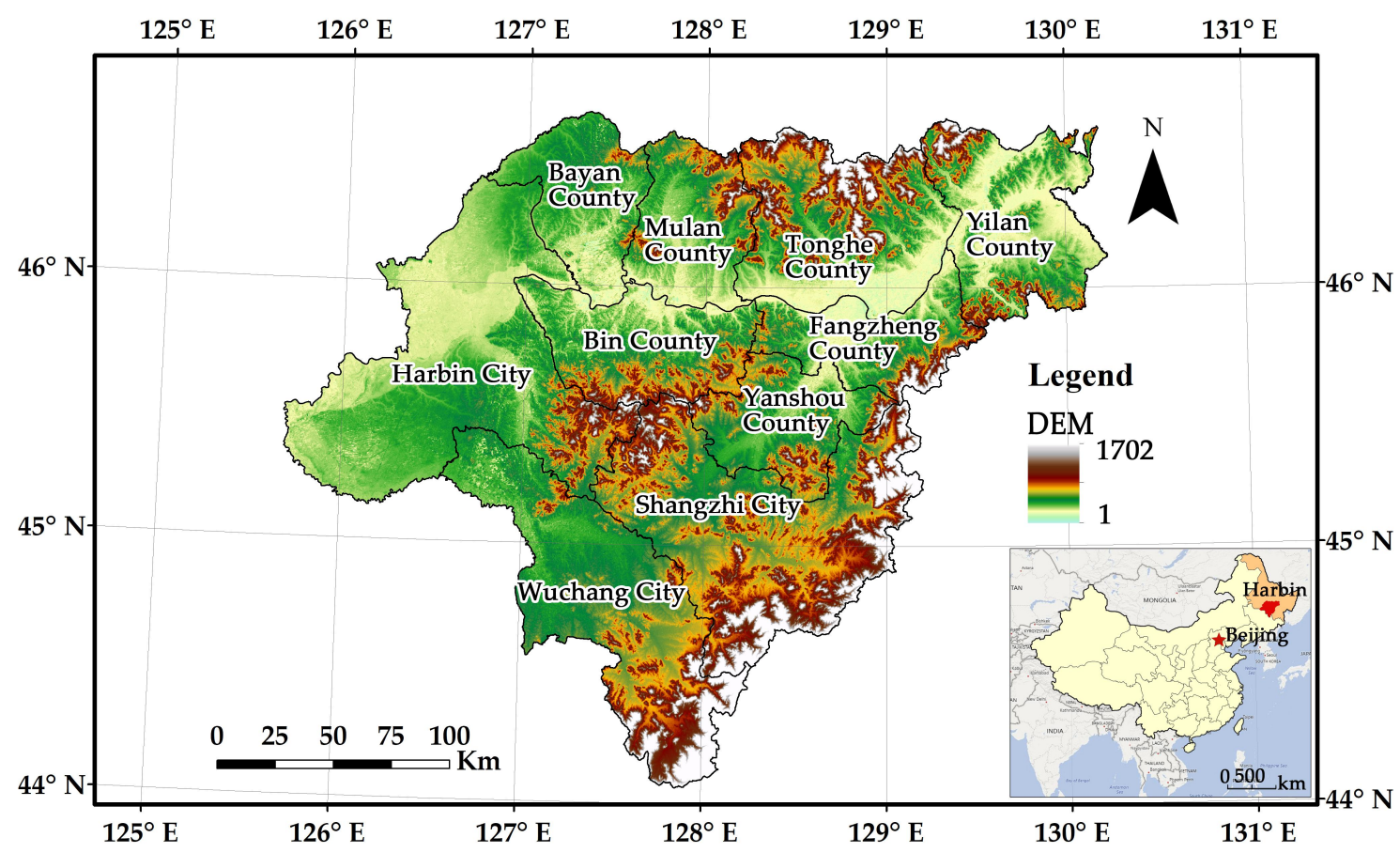

Figure 2. The geographical location of the study area. Source: (Guo and Bai, 2019).

In this paper, the land use and cover data (2015) are provided by Beijing Digital View Technology CO., Ltd. Digital elevation model (DEM) data are downloaded from the 'Geospatial Data Cloud' website. The NDVI (Normalized Difference Vegetation Index) is extracted according to MODIS data. Water resources, climate, and productive potential of the land data in this paper can be obtained by 'Resource and Environment Science and Data Center'. Other data sources include Harbin statistical yearbook, historical weather website, Harbin Development and Reform Commission, and so on.

\section{Results}

\subsection{Green infrastructure assessment in Harbin}

Based on Maryland's green infrastructure assessment practice (Weber, Sloan and Wolf, 2006) and local characteristics of Harbin, this paper identifies Harbin's green infrastructure network firstly and then selects indicators from the perspectives of ecosystem services and ecological sensitivity to assess green 
infrastructure in 2015 for Harbin. The ecosystem services value is computed by the corrected equivalents of ecosystem service value which is obtained by grain yield and prices in 2015 of Harbin. The GI assessment indicators in the view of ecological sensitivity comprise natural reserves, forest parks, scenic spots, woodlands, cultivated land, rivers, lakes, reservoirs, slope, topographic relief, and road. The results of the green infrastructure assessment in 2015 for Harbin can be produced by weights from experts scoring method (Figure 3).

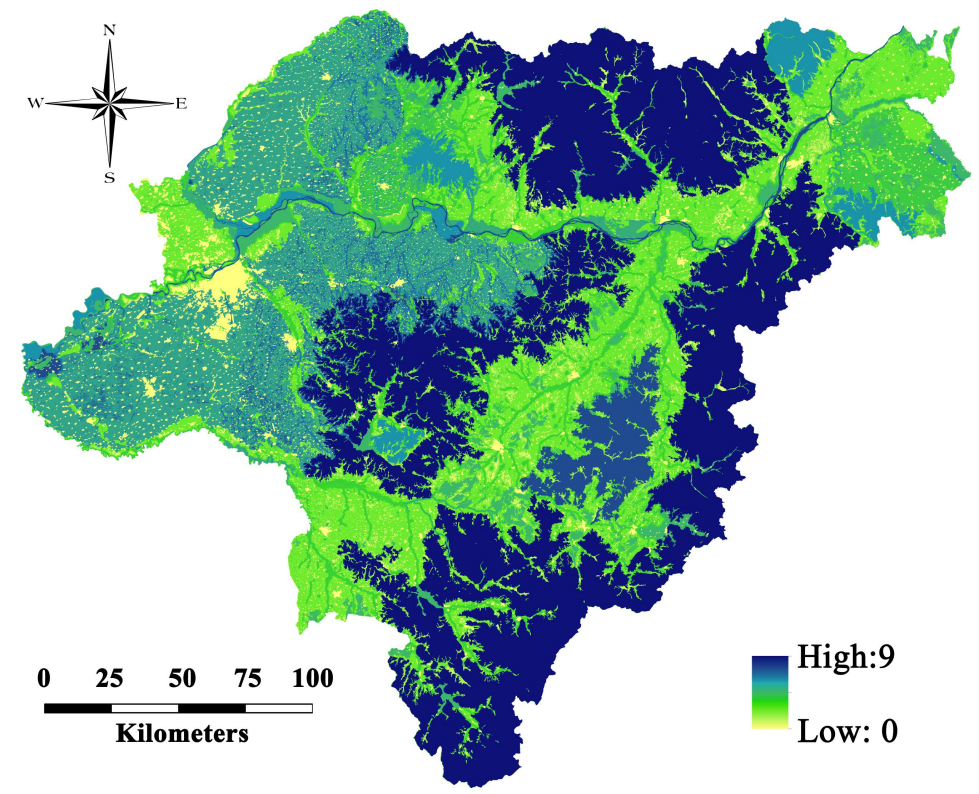

Figure 3. The results of the green infrastructure assessment in $\mathbf{2 0 1 5}$ for Harbin. Source: the authors.

The 0 value in Figure 3 refers to current urban-rural construction areas. It can be seen that the higher value mainly distributes in the east of Harbin. These areas are of key ecological significance and should be prohibited for urban-rural development and construction in the future.

\subsection{The suitability evaluation results of land development based on green infrastructure assessment in Harbin}

Generally, the higher the value of green infrastructure assessment is, the more important the ecological significance of green infrastructure is, and the higher the importance of ecological protection is. Consequently, the results of the importance of ecological protection in Harbin (Figure 4) can be created according to the results of the green infrastructure assessment. Important and extremely important areas are classified as ecological red line control zone in ecological spaces. The suitability evaluation of the agricultural production and urban-rural construction are carried out for other areas. Coupling with the current situation of agricultural and construction land in Harbin, ecological spaces, agricultural spaces, and urban-rural construction spaces of Harbin can be delineated (Figure 5). The percentage of each type of space in the total administrative area was $51.4 \%$ (ecological spaces), $4.4 \%$ (urban-rural construction spaces), and $44.0 \%$ (agricultural spaces), separately. In which, ecological spaces consist of ecological red line control zones (about $46.7 \%$ ) and other ecological space (4.7\%). 


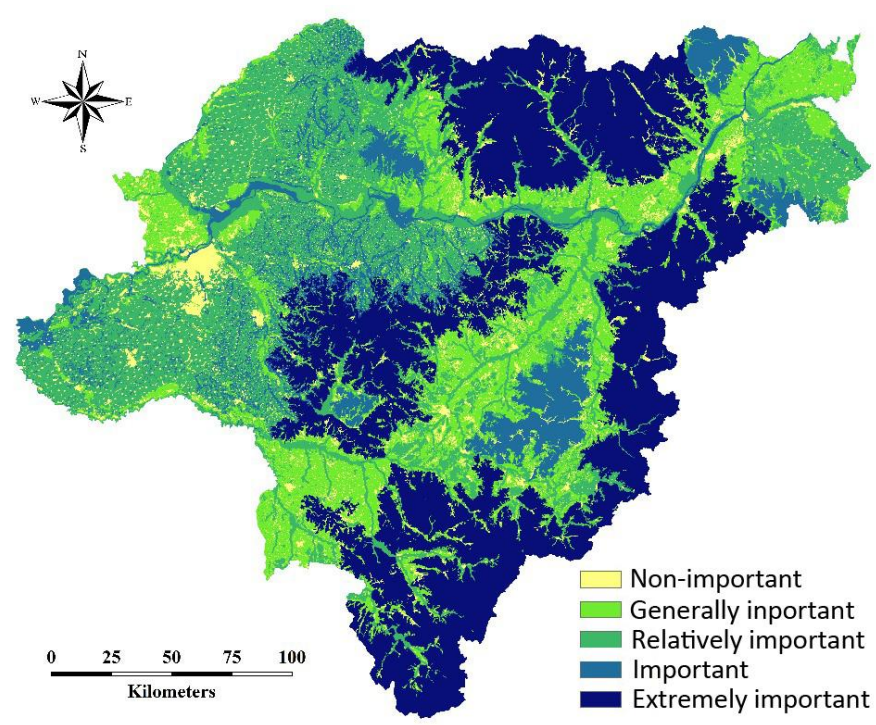

Figure 4. The results of the importance evaluation of ecological protection in 2015 for Harbin. Source: the authors.

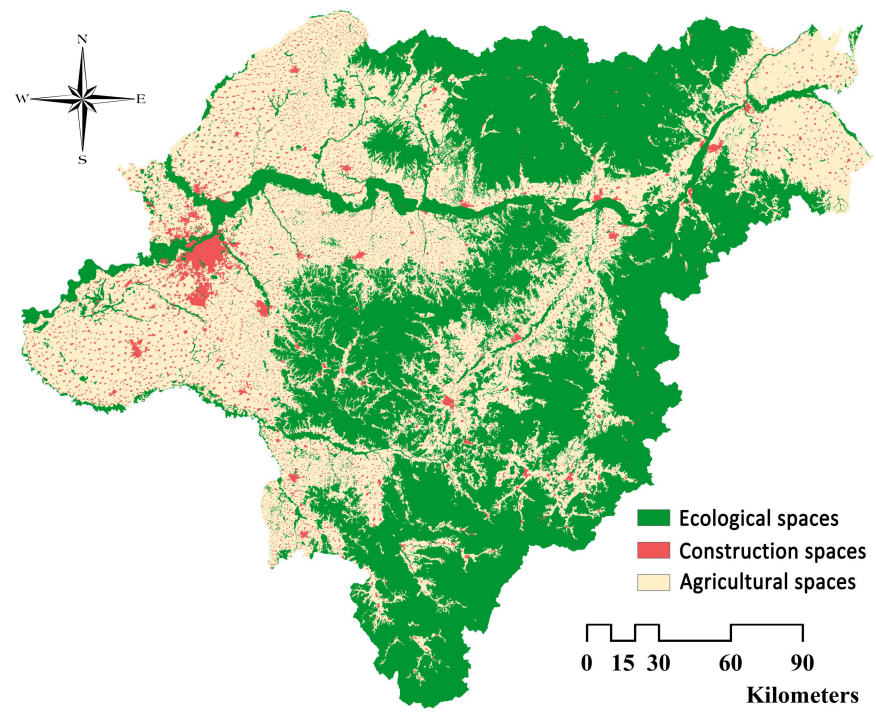

Figure 5. The results of the delineation of functional spaces in $\mathbf{2 0 1 5}$ for Harbin. Source: the authors.

\section{Discussions and conclusions}

This paper proposes the framework for the suitability evaluation of land development based on green infrastructure assessment, and apply this framework to preliminary delineate Harbin's three functional spaces: ecological spaces, agricultural spaces, and urban-rural construction spaces. To protect ecological spaces and available land resources for sustainable agricultural production, the sequence of dividing functional spaces in this paper is ecological spaces, agricultural spaces, and then construction spaces. For Harbin's land development planning in the future, measures for ecological spaces will focus on protection and restoration, while measures for agricultural and construction spaces will separately be limited development and optimized development.

Because of the limitation of data acquisition, the suitability evaluation of land development only uses a few indicators to obtain the results of this paper. Therefore, the evaluation results exist limitations and also are a fuzzy problem. This paper focuses on the feasibility of land suitability evaluation based on 
green infrastructure assessment, the scope of each functional space is determined according to data of 2015 in Harbin. For land development planning in the future, the scope of three functional spaces can change. This could be discussed in our next study.

According to the case study of Harbin, evlauting the suitability of land development based on green infrastructure assessment is feasible. The important and extremely important areas obtained by the results of green infrastructure assessment are classified as the ecological red line control zone. Based on data of 2015 in Harbin, the area of ecological spaces is the largest, followed by agricultural spaces, while the area of urban-rural construction spaces is the smallest. To achieve optimum utilization of each functional space, some differential development measures should be taken in the land spatial planning of Harbin.

\section{References}

Alcamo, J. et al. (2003) Millennium Ecosystem Assessment: Ecosystems and Human Well-being. Washington, D.C. Available at: www.islandpress.org (Accessed: 1 April 2020).

Conbere, S. et al. (2014) Enhancing Sustainable Communities with Green Infrastructure. Available at: www.epa.gov/smartgrowth (Accessed: 10 November 2018).

Ely, M. and Pitman, S. (2014) Green Infrastructure: Life support for human habitats. Adelade, Australia: Botanic Gardens of Adelaide, Department of Environment, Water and Natural Resources. Available at: http://apo.org.au/node/135761 (Accessed: 2 December 2018).

European Commission (2012) The Multifunctionality of Green Infrastructure, Science for Environment Policy. doi: 10.1073/pnas.1216303110.

Fan, J. (2019) Guidelines for evaluation methods of carrying capacity of resources and environment and suitability of land development. 1st edn. Beijing: Science Press.

Guo, R. and Bai, Y. (2019) 'Simulation of an urban-rural spatial structure on the basis of green infrastructure assessment: The case of Harbin, China', Land. MDPI AG, 8(12), p. 196. doi: 10.3390/LAND8120196.

Hopkins, L. D. (1977) 'Methods for generating land suitability maps: A comparative evaluation', Journal of the American Planning Association. Taylor \& Francis Group, 43(4), pp. 386-400. doi: 10.1080/01944367708977903.

Joerin, F., Thérialult, M. and Musy, A. (2001) 'Using GIS and outranking multicriteria analysis for land-use suitability assessment', International Journal of Geographical Information Science, 15(2), pp. 153-174. doi: 10.1080/13658810051030487.

Kalogirou, S. (2002) 'Expert systems and GIS: An application of land suitability evaluation', Computers, Environment and Urban Systems. Pergamon, 26(2-3), pp. 89-112. doi: 10.1016/S0198-9715(01)00031-X.

Liu, Binyi et al. (2013) 'Studies and Practices on Urban Green Infrastructure', Chinese Landscape Architecture, 29(03), pp. 6-10. doi: CNKI:SUN:ZGYL.0.2013-03-005.

Naumann, S. et al. (2011) Design, implementation and cost elements of Green Infrastructure projects. Washington, USA \& London, UK. Available at:

https://www.ecologic.eu/sites/files/project/2014/documents/design-implementation-cost-elements-of-greeninfrastructure-projects-2011-naumann_0.pdf (Accessed: 24 January 2019).

Nisar Ahamed, T. R., Gopal Rao, K. and Murthy, J. S. R. (2000) 'GIS-based fuzzy membership model for cropland suitability analysis', Agricultural Systems. Elsevier, 63(2), pp. 75-95. doi: 10.1016/S0308-521X(99)00036-0.

Prakash TN (2003) Land Suitability Analysis for Agricultural Crops: A Fuzzy Multicriteria Decision Making Approach.

Sicat, R. S., Carranza, E. J. M. and Nidumolu, U. B. (2005) 'Fuzzy modeling of farmers' knowledge for land suitability classification', Agricultural Systems. Elsevier, 83(1), pp. 49-75. doi: 10.1016/j.agsy.2004.03.002. 
The North West Green Infrastructure Think Tank (2008) North West Green Infrastructure Guide. UK. Available at: https://www.yumpu.com/en/document/read/46437820/north-west-green-infrastructure-guide (Accessed: 25 January 2019).

Weber, T., Sloan, A. and Wolf, J. (2006) 'Maryland's Green Infrastructure Assessment: Development of a comprehensive approach to land conservation', Landscape and Urban Planning. Elsevier, 77(1-2), pp. 94-110. doi: 10.1016/J.LANDURBPLAN.2005.02.002.

Wu, Y. et al. (2018) 'Regional Green Infrastructure Space Pattern Identification Based on Urban Air Conditioning', Landscape Architecture, (01), pp. 33-37. doi: 10.14085/j.fjyl.2018.01.0033.05.

Xie, G. et al. (2015) 'Improvement of the Evaluation Method for Ecosystem Service Value Based on Per Unit Area', Journal of Natural Resources, 30(8), pp. 1243-1254. doi: 10.11849/zrzyxb.2015.08.001.

Xing, Y., Jones, P. and Donnison, I. (2017) 'Characterisation of nature-based solutions for the built environment', Sustainability (Switzerland), p. 149. doi: 10.3390/su9010149. 